\title{
ANALISA PERAWATAN EXHAUST VALVE MESIN INDUK UNTUK MENUNJANG PENGOPERASIAN MESIN DI KAPAL WESTSEA GAIL
}

\author{
Paulus pongkessu ${ }^{1)}$ Mahadir Sirman ${ }^{2)}$ Helmonius Toding ${ }^{3)}$ \\ Politeknik IImu Pelayaran Makassar \\ Jalan Tentara Pelajar No. 173 Makassar, Kode pos. 90172 \\ Telp. (0411) 3616975; Fax (0411) 3628732 \\ E-mail:pipmks@pipmakassar.com
}

\begin{abstract}
ABSTRAK
Penelitian ini bertujuan untuk lebih memahami cara melaksanakan perawatan katup buang mesin induk dan untuk lebih memahami faktorfaktor yang dapat menunjang perawatan katup buang mesin induk sehingga pengoperasian mesin induk dapat dilakukan sesuai dengan prosedur. Penelitian ini dilaksanakan pada kapal Westsea Gail selama 12 bulan yaitu pada tanggal 05 Mei 2017 sampai dengan tanggal 15 Mei 2018. Sumber data yang digunakan yaitu data primer dan data sekunder, sedangkan metode analisis yang penulis gunakan yaitu analisis kualitatif yang diperoleh dalam bentuk variabel berupa informasi yang berasal dari atas kapal Westsea Gail. Hasil yang diperoleh setelah dianalisis menunjukkan bahwa pertama : terjadinya kerusakan pada katup buang di karenakan tidak dilaksanakannya perawatan sesuai dengan jadwalnya, kedua : Kegagalan katup yang mengalami pembebanan termal karena suhu tinggi dan tekanan di dalam silinder. Kondisi kegagalan karena suhu tinggi pada sifat mekanik bahan dan korosi terlihat berupa patahan pada lapisan katup buang serta adanya pengendapan (deposit) baik pada katup buang (exhaust valve) atau katup hisap.
\end{abstract}

Kata kunci : Katup Buang,Suhu Tinggi,Kerusakan Katup

\section{PENDAHULUAN}

Dalam menunjang kegiatan operasionalnya, maka peranan kapal laut tidak terlepas hubungannya, dengan keberadaan mesin induk sebagai pesawat penggerak utama di atas kapal, serta dibantu oleh pesawatpesawat atau mesin bantu lainnya saling terkait dan merupakan kelengkapan dalam kelancaran pengoperasian kapal. Bagian mesin yang sangat penting adalah silinder karena merupakan jantung mesin dan tempat bahan bakar dibakar dan daya ditimbulkan. 
Salah satu komponen yang terdapat pada motor induk khususnya mesin penggerak utama adalah exhaust valve yang merupakan sebagai pintu pembuangan sisa-sisa gas pembakaran sebagai suatu saluran gas buang. Pada mesin diesel secara umum terdapat 2 jenis, yaitu katup masuk (inlet) dan katup buang (exhaust), di kapal tempat penelitian dilakukan, menggunakan motor diesel 4 tak diesel engine MITSUBISHI S8U-M.P.T.N Untuk menjaga pengoperasian mesin induk tetap sempurna, perlu dilakukan suatu tindakan pemeriksaan dan perawatan pada komponen exhaust valve secara berkelanjutan guna menjaga kondisi serta keandaan dari mesin induk.

Apabila komponen tersebut kurang mendukung maka akan mengakibatkan turunnya tenaga mesin, sehingga mesin induk tidak bekerja dengan stabil yang pada akhirnya dapat menghambat operasional kapal. Berkaitan dengan hal tersebut di atas maka penulis mengadakan penelitian tentang menurunnya perawatan exhaust valve pada mesin induk yang dituangkan dengan judul "analisa perawatan exhaust valve mesin induk untuk menunjang pengoperasian mesin di kapal WESTSEA GAIL"

perawatan exhaust valve pada mesin induk di kapal yang tidak dilaksanakan. Yaitu :Bagaimana perawatan exhaust valve pada mesin induk untuk menunjang pengoperasian mesin kapal?

\section{TINJAUAN PUSTAKA}

Menurut [1], katup buang merupakan katup yang dipergunakan sebagai pintu pembukaan sisa-sisa gas pembakaaran sebagai suatu saluran buang. Menurut [10], kapal adalah salah satu dari peralatan yang menggunakan Motor, mekanisme katup yang terdapat pada motor yang berfungsi untuk mengatur pemasukan bahan, mengatur pemasukan bahan bakar dan udara ke dalam silinder dan mengatur pembuangan. Untuk mendukung pembahasan mengenai perawatan exhaust valve maka perlu diketahui teori-teori penunjang atau juga pengertian- 
pengertian yang diambil dari beberapa kepustakaan yang berkaitan dengan pembahasan skripsi ini. Katup buang adalah salah satu jenis katup yang terdapat pada motor disel baik itu 4 tak maupun 2 tak yang berfungsi sebagai katup untuk membuka jalan keluar dari gas sisia hasil dari pembakaran keluar dari dalam ruang kompresi ke exhaust manifold.

Menurut [5] mengemukakan tujuan perawatan adalah sebagai berikut "Perawatan adalah untuk menghasilkan suatu alat pengelolah yang lebih baik dalam meningkatkan keselamatan pada awak kapal dan perawatannya".

Pada dasarnya apa yang diharap dari keberadaan perawatan mesin tidak lain adalah untuk meningkatkan efektifitas serta porsi keuntungan bagi pemilik perusahaan. Hal ini bisa dimungkinkan, karena dengan perawatan kapasitas produksi suatu mesin hingga estimate umur ekonomisnya. Di dalam kenyataan yang tidak sedikit bisa diamati di lapangan, bahwa keberhasilan pekerjaan perawatan mesin justru menuntut kerja sama yang baik dan kompak serta terorganisir dalam team work yang baik.Perawatan merupakan suatu cara yang dilakukan untuk menjaga kondisi yang diinginkan. Dalam usaha untuk menggunakan mesin secara terus-menerus agar kelanjutan produksi dapat terjamin maka perlu diadakan perawatan mesin sebaik mungkin. Perawatan itu meliputi : pengecekan, pelumasan (lubrication) dan perbaikan atau reparansi atas kerusakan yang ada serta penyesuaian atau penggantian suku cadang atau komponen-komponen yang terdapat pada mesin-mesin tersebut. Semua tugas ini merupakan tugas dari bagian perawatan. Dengan kata lain perawatan mesin-mesin dapat diartikan sebagai kegiatan untuk memelihara atau menjaga peralatan mesin-mesindan mengadakan perbaikan atau penyesuaian, penggantian yang diperlukan agar supaya tercipta suatu keadaan operasi yang diharapkan. 


\subsection{Sistem Perawatan Berencana (Plan Maintenance System)}

Menurut [4] mengatakan, planning is deciding in advance what is to be done. Jadi perencanaan adalah penentuan terlebih dahulu apa yang akan dikerjakan.

Sistem perawatan mesin induk dikapal juga bisa menerapkan sistem Plan Maintenance Sistem, dimana tujuan dari sistem ini adalah untuk penyiapan perangkat manajemen yang lebih baik dan meningkatkan keselamatan, baik awak kapal maupun peralatan.

\subsection{Tujuan perawatan}

a. Untuk memungkinkan kapal dapat beroperasi secara reguler dan meningkatkan keselamatan, baik awak kapal maupun peralatan.

b. Untuk membantu perwira dalam menyusun rencana dan mengatur dengan yang lebih baik, sehingga kinerja kapal meningkat, dan mencapai maksud dan tujuan yang sudah ditetepkan oleh para manejer dikantor pusat.

c. Untuk memperhatikan pekerjaan-pekerjaan yang paling mahal berkaitan dengan waktu ndan material, sehingga mereka yang terlibat benar-benar meneliti dan dapat meningkatkan metode untuk mengurangi biaya.

d. Agar dapat melaksanakan pekerjaan secara sistematiks tanpa mengabaikan hal-hal terkait, dan melakukan pekerjaannya dengan cara paling ekonomis.

e. Untuk memberikan kesinambungan perawatan sehingga perwira yang baru naik kapal dapat mengetahui apa yang telah dikerjakan dan apalagi yang harus dikerjakan.

2.3. Perawatan dan perbaikan (spesifikasi, jadwal, dan lain-lain).

a. Perawatan insidentil; artinya kita membiarkan mesin bekerja sampai rusak pada umumnya model ini sangat mahal, oleh karena itu beberapa bentuk sistem perencanaan diterapkan dengan mempergunakan sistem perawatan berencana, dengan tujuan untuk 
memperkecil kerusakan dan beban bekerja dari suatu pekerjaan perawatan yang diperlukan.

b. Perawatan pencegahan terhadap perawatan perbaikan.

Perawatan ini berfungsi untuk mencegah terjadinya kerusakan atau bertambahnya kerusakan dalam tahap ini. Hal ini berarti bahwa harus digunakan metode tertentu untuk menelusuri perkembangan yang terjadi.

c. Perawatan periodik pemantauan kondisi.

Perawatan pencegahan biasanya terjadi dari pembukaan secara periodik mesin dan perlengkapan untuk menentukan apakah diperlukan penyetelan-penyetelan dan pengantian-pengantian. Jangka waktu inspeksi demikian biasanya didasarkan atas jam kerja mesin atau waktu kalender.

A. Sistem Pembuangan

Cara Kerja Katup Buang Hidrolik

Menurut Maanen [8] torak dari pompa actuator (penggerak pompa) digerakkan oleh nok. Katup tekanan baik mencegah aliran balik minyak ke system suplai selama langkah ke atas dari torak. Minyak yang dipindahkan oleh torak mengalir keluar dari silinder OE1 melalui saluran ke silinder OE2 diatas katup buang.

\section{a. Pembuangan Katup}

Bila minyak dalam ruang OE2 tidak menerima tekanan, maka katup buang ditahan dalam keadaan tertutup oleh tekanan udara dalam silinder. Bila oleh torak minyak ditekan ke silinder dengan torak, maka katup akan membuka melawan tekanan udara oleh tekanan udara hidrolik. Kecepatan katup dan dan tinggi angkatnya akan ditentukan oleh bentuk nok dan tinggi nok.

Bila katup buang terbuka, maka gas buang akan mengalir dengan kecepatan tinggi melalui sayap. Akibatnya adalah terjadi sebuah kopel pada batang katup sehingga katup akan berputar dari sebuah putaran. Oleh karena pegas udara tidak mengalami gangguan banyak, maka 
katup akan berputar dengan sebuah kopel kecil. Dengan rotasi katup tersebut maka akan dihasilkan pembagian suhu yang merata pada katup dan batang katup sehingga perubahan bentuk dari katup dan penutupan yang tidak sempurna dapat dicegah. Dengan adanya rotasi tersebut maka tempat duduk katup juga tetap akan bersih

b. Penutup Dari Katup

Bila rol telah melalui titik tertinggi nok, maka torak akan menurun lagi sehingga tekanan dalam system hidrolik akan hilang. Tekanan udara dalam silinder, dijaga pada harga 5,5 atau 6 bar menekan silinder dengan katup buang dan torak hidrolik kearah atas lagi (pegas udara). Sewaktu penutupan dari katup, maka oleh pena peredam dicegah katup memukul tempat duduk dengan gaya yang besar.

B. Komponen-Komponen Sistem Buang

Menurut [9] sistem buang adalah gabungan antara alat yang dilalui gas buang untuk meninggalkan mesin. Adapun bagian dan komponenkomponen dari sistem buang antara lain, yaitu

a. Katup buang

Operasi yang memuaskan dari katup buang tergantung padadua keadaan yaitu, pengaturan waktu yang tepat dan dudukan yang baik. Pengaturan waktu dapat tidak tepat lagi karena keausan berlebihan dari nok dan lebih sering lagi karena bertambahnya celah antara nok dan pengikut nok atau pengikut nok dan batang dorong. Oleh sebab itu setiap saat harus diperiksa terhadap spesifikasi yang diberikan dalam buku petunjuk yang disediakan oleh pembuat mesin. Dimana katup buang berfungsi sebagai pengatur pegeluaran gas buang dari dalam silinder.

\section{b. Pipa Cabang Buang}

Pipa cabang buang digunakan pada mesin silinder jamak atau banyak untuk menyambung lubang buang dari masing-masing silinder kepada pipa cabang buang sekutu. Dalam mesin kecil pipa cabang buang 
terbuat dari besi cor atau baja cor dan biasanya mempunyai jaket air pendingin

Adapun tanda-tanda terjadinya kerusakan atau kebocoran pada katup buang menurut [5] yaitu:

a. Gas buang berwarna sangat hitam dan tebal

b. Temperatur gas buang meningkat tinggi dari temperatur normal $\left(350^{\circ} \mathrm{C}\right)$

c. Temperatur air pendingin naik dari temperatur normal $\left(60-65^{\circ} \mathrm{C}\right)$

d. Timbulnya bunga api pada cerobong

e. Putaran Motor turun

\section{METODE PENELITIAN}

Lokasi penelitian adalah kamar mesin induk kapal Westsea Gail yang menjadi objek penelitian adalah exhaust valve mesin induk, penelitian dan pengumpulan data-data dilaksanakan pada saat melaksanakan praktek di atas kapal Westsea Gail.

Objek yang akan diteliti pada penelitian ini adalah dampak yang timbul apabila perawatan exhaust valve pada mesin induk yang tidak dilaksanakan sesuai dengan jadwal perawatan serta akibatnya pada pengoperasian kapal.

1. Observasi

Mencatat data temperature gas buang pada kondisi abnormal

2. Studi Pustaka

Membaca dan menelaah buku-buku atau dokumen-dokumen baik yang ada di perpustakaan atau pun dokumen yang diperoleh dari tempat lain yang relefan dengan permasalahan yang mengenai Exhaus valve pada Mesin Induk dan cara penenggulangannya.

C. Jenis Dan Sumber Data

1. Jenis Data

Jenis data yang dipergunakan dalam penelitian ini yakni data kualitatif yaitu data yang diperoleh berupa informasi-informasi sekitar 
pembahasan secara tulisan adalam perawatan exhaust valve mesin induk.

2. Sumber data

Data temperature gas buang pada enam silinder dapat dilihat pada tabel data.

C. Metode Penelitian

Penelitian ini dilakukan dengan menggunakan metode kualitatif dimana kegiatan yang dilakukan dengan memulai langkah mengamati objek yang diteliti dan mencatat data-data yang menunjang sewaktu melaksanakan praktek laut di atas kapal Westsea Gail kemudian membahas objek tersebut untuk dipaparkan secara rinci. Data yang diperoleh dengan tujuan untuk memberikan informasi mengenai perencanaan terhadap masalah yang timbul berhubungan dengan judul penelitian ini.

\section{HASIL PENELITIAN}

Berdasarkan data yang penulis dapatkan, maka yang akan dibahas adalah penyebab terjadinya kerusakan komponen exhaust valve akibat tidak melaksanakan jadwal perawatan. komponen mekanisme katup tidak dapat dihindarkan karena penggunaan yang terus menerus. Perubahan yang tidak dapat dihindari tersebut akibat adanya gesekan, temperatur yang tinggi, tumbukan atau melakukan kontak dan kotoran pada system penyaringan pelumasan selama penggunaan.

Tabel 1 Data temperatur gas buang pada kondisi abnormal

\begin{tabular}{|c|c|c|c|c|c|c|c|}
\hline \multirow{2}{*}{$\begin{array}{c}\text { Hari/Tangg } \\
\text { alJam } \\
\text { Jaga }\end{array}$} & \multicolumn{6}{|c|}{ Temperatur Gas Buang ( ${ }^{0}$ C ) } & \multirow{2}{*}{$\begin{array}{c}\text { Keterang } \\
\text { an }\end{array}$} \\
\cline { 2 - 7 } & $\mathbf{1}$ & $\mathbf{2}$ & $\mathbf{3}$ & $\mathbf{4}$ & $\mathbf{5}$ & $\mathbf{6}$ & \\
\hline Rabu, & 361 & 340 & 360 & 350 & 340 & 390 & $\begin{array}{c}\text { Abnormal } \\
\text { pada } \\
\text { silinder 6 } 6\end{array}$ \\
\hline
\end{tabular}




\begin{tabular}{|c|c|c|c|c|c|c|c|}
\hline $00.00-04.00$ & & & & & & & \\
\hline $\begin{array}{c}\text { Rabu } \\
\text { 02-08-2017 } \\
\text { 04.00-08.00 }\end{array}$ & 362 & 345 & 350 & 340 & 355 & 391 & $\begin{array}{c}\text { Abnormal } \\
\text { pada } \\
\text { silinder } 6\end{array}$ \\
\hline $\begin{array}{c}\text { Rabu, } \\
\text { 02-08-2017 }\end{array}$ & 362 & 345 & 340 & 360 & 355 & 391 & $\begin{array}{c}\text { Abnormal } \\
\text { pada } \\
\text { silinder } 6\end{array}$ \\
\hline $\begin{array}{c}\text { Rabu, } \\
\text { 02-08-2017 } \\
12.00-16.00\end{array}$ & 360 & 350 & 350 & 355 & 350 & 393 & $\begin{array}{c}\text { Abnormal } \\
\text { pada } \\
\text { silinder } 6\end{array}$ \\
\hline $\begin{array}{c}\text { Rabu, } \\
\text { 02-08-2017 } \\
16.00-20.00\end{array}$ & 360 & 350 & 355 & 360 & 360 & 391 & $\begin{array}{c}\text { Abnormal } \\
\text { pada } \\
\text { silinder } 6\end{array}$ \\
\hline
\end{tabular}

Sumber : Data Temperatur Gas Buang di Kapal Westsea Gail

Tabel 1 menunjukkan bahwa silinder No.6 suhu gas buangannya melebihi dari temperatur normal $(340-365)^{\circ} \mathrm{C}$. Maka dari kasus seperti pada tabel diatas adalah akibat dari tidak dilaksanakannya suatu penggantian atau perawatan pada katup buang Menurut Maleev katup buang berfungsi sebagai pengatur pegeluaran gas buang dari dalam silinder Oleh sebab itu setiap saat harus diperiksa terhadap spesifikasi yang diberikan dalam buku petunjuk yang disediakan oleh pembuat mesin. Katup buang (exhaust valve) berada dalam suatu silinder head mesin/pada tempat tersembunyi dalam body mesin sehingga tidak dapat diperiksa secara visual, namun dapat diketahui melalui akibatakibat pada mesin. 
A. Pemecahan Masalah Hasil Analisa

Solusi yang dilakukan oleh engineer dan crew mesin untuk menanggulangi kerusakan dan perawatan pada katup buang (exhaustvalve), agar dapat memenuhi standar pengoperasian pada manual book maka perlu dilakukan perbaikan serta penggantian pada komponen-komponen katup tersebut. Sebelum melaksanakan perbaikan maka perlu dilakukan rencana kerja untuk membagi tugas serta membahas tentang keselamatan kerja agar tidak terjadi insiden saat melakukan perbaikan atau pekerjaan, berikut adalah hal yang dilakukan untuk melakukan perbaikan sesuai SOP pada manual book

1. Melakukan penggantian komponen-komponen katup buang (exhaust valve) yang sudah mengalami kerusakan.

2. Melakukan pembersihan dari kerak-kerak pada setiap komponen mekanisme katup dan men-skir permukaan daun katup agar tidak terdapat celah antara daun katup dan dudukan katup akibat kerak yang menempel.

3. Menyetel celah katup sesuai dengan instruksi manual book.

Katup yang diatur terlalu sempit akan mengakibatkan katup tersebut tidak akan menutup dengan baik setelah mesin bekerja pada temperatur normal dan pada bagian batang katup akan memuai secara berlebihan, akibatnya adalah katup terbakar akibat gas panas yang melewati katup setelah pembakaran. Katup yang celahnya terlalu longgar akan terlambat membuka dan menutup terlalu cepat. Akibatnya adalah menurunnya daya mesin sehingga mesin tersebut akan kurang mengeluarkan tenaga, boros bahan bakar dan emisi yang tinggi. Dari Hasil Pengamatan yang dilakukan oleh Third Enginer bersama Cadet terlihat bahwa mesin jalannya lambat, dan panas sehingga membutuhkan perbaikan yang dilakukan bersama dan dalam pengawasan Chief Enginer. 
Tabel 4.2. Data temperatur gas buang pada saat setelah diperbaiki

\begin{tabular}{|c|c|c|c|c|c|c|c|}
\hline \multirow{3}{*}{$\begin{array}{c}\text { Hari/Tanggal } \\
\text { Jam Jaga }\end{array}$} & \multicolumn{6}{|c|}{ Temperatur Gas Buang $\left({ }^{\circ} \mathrm{C}\right)$} & \multirow{3}{*}{$\begin{array}{c}\text { Ketera } \\
\text { ngan }\end{array}$} \\
\hline & \multicolumn{6}{|c|}{ Cylinder } & \\
\hline & 1 & 2 & 3 & 4 & 5 & 6 & \\
\hline $\begin{array}{c}\text { Selasa, } \\
22-08-2017 \\
00.00-04.00\end{array}$ & 360 & 345 & 360 & 355 & 350 & 350 & Normal \\
\hline $\begin{array}{c}\text { Selasa, } \\
22-08-2017 \\
04.00-08.00\end{array}$ & 355 & 350 & 355 & 350 & 350 & 353 & Normal \\
\hline $\begin{array}{c}\text { Selasa, } \\
22-08-2017 \\
08.00-12.00\end{array}$ & 360 & 345 & 360 & 357 & 350 & 344 & Normal \\
\hline $\begin{array}{c}\text { Selasa, } \\
22-08-2017 \\
12.00-16.00\end{array}$ & 350 & 355 & 355 & 350 & 345 & 350 & Normal \\
\hline $\begin{array}{c}\text { Selasa, } \\
22-08-2017 \\
16.00-20.00\end{array}$ & 355 & 348 & 355 & 349 & 350 & 355 & Normal \\
\hline
\end{tabular}

Sumber : Data Hasil Pengamatan Temperatur Gas Buang di Kapal Westsea Gail setelah perbaikan.

Dalam hal-hal tersebut di atas kita lebih mengutamakan penerapan untuk perawatan dan perbaikan.Namun walaupun kita mempunyai manajemen yang tepat dan terarah tapi masing-masing diatas kapal tidak boleh terus mengabaikan dan mengendorkan akan kedisiplinan dalam bekerja, karena kunci keberhasilan suatu perawatan mesin induk adalah yang pertama mendisiplinkan sumber daya manusianya agar tidak kendor dalam melakukan suatu pekerjaan dan setelah itu baru memberikan suatu 
keterampilan, pengarahan, sosialisasi dan pengetahuan tentang permesinan kapal kepada para perwira-perwira dan seluruh crew khususnya bagian mesin agar memiliki kemampuan bekerja lebih handal dan berkualitas.

Untuk menghindari terjadinya pemeliharaan insidentil (breakdown maintenance), yaitu:

1. Penguasaan akan manajemenperawatan sehingga bisa mencapai keberhasilan.

2. Kerjasama yang baik antara bagian untuk menganalisa pekerjaan.

3. Tenaga kerja perawatan.

4. Aliran laporan.

5. Efektifitas dan kebiasaan bekerjasama dengan pekerja.

6. Kemungkinan terdapatnya efek perubahan-perubahan jadwal kerja.

7. Waktu yang dibutuhkan, kepada dan berapa lama sampai pekerjaan dapat diselesaikan dan suku cadang.

Dilihat dari kemungkinan efek yang diakibatkan dari perubahan jadwal di atas, maka hendaklah penundaan jadwal pekerjaan dilakukan tetap pada bulan yang sama dengan jadwal yang sesuai PMS. Untuk itu KKM bersama masinis I hendaknya lebih tegas dalam penjadwalan perawatan dan dilaksanakan dengan professional. Dilihat dari Pengamatan kadang perawatan tidak sesuai dengan jadwal bahkan kadang terlambat sampai 2 bulan dari waktu yang dijadwalkan. Ini yang biasa mengakibatkan timbul masalah pada alat-alat yang harus dilakukan perawatan.

\section{B. Pembahasan}

Dalam pembahasan ini terbagi atas tiga bagian yaitu:

\section{Plan Maintenance System (PMS)}

Suatu bahan atau material mempunyai batas kerja yang maksimal, begitu pula pada komponen-komponen katup buang mempunyai batas kerja . Jadi apabila seating katup buang telah melebihi jam kerja dan 
belum dilakukan penggantian, maka lama kelamaan seating tersebut akan mengalami kelelahan bahan maka dari itu untuk menghindari kerusakan akibat kelelahan bahan dianjurkan untuk mengganti seating tersebut sesuai dengan jam kerjanya.Mengadakan jadwal inspeksi yaitu pekerjaan pemeliharaan agar efektif maka harus dilakukan secara menyeluruh. Suatu jadwal pelayanan pemeliharaan harus diuraikan dalam setiap instalasi dan jadwal ini harus diikuti untuk mengadakan operasi. Dalam jadwal inspeksi harus disisipkan jumlah batas maksimum dari jam operasi diantara inspeksi dari bagian yang terdaftar. Jika jadwal pelayanan instalasi terurai siapapun pengganti yang akan bekerja di kapal yang pasti akan berganti dengan orang yang berbeda akan dapat melaksanakan pemeliharaan dengan baik, dan alat-alat akan dapat terpelihara dengan baik dan selalu siap untuk digunakan.

Berikut ini jadwal perawatan / pemeriksaan serta cara penanganan sesuai dengan komponen yang dibahas :

Tabel 4.3. Data jadwal perawatan / pemeriksaan komponen

\begin{tabular}{|c|c|c|}
\hline $\begin{array}{c}\text { Jenis } \\
\text { pengecekan }\end{array}$ & Waktu pengecekan & Cara penanganan \\
\hline Exhaust Valve & $1500-2000 \mathrm{jam}$ & $\begin{array}{c}\text { Mengganti dudukan } \\
\text { katup(valve seat) }\end{array}$ \\
\hline $\begin{array}{c}\text { Komponen } \\
\text { Exhaust valve }\end{array}$ & $1500-4000 \mathrm{jam}$ & $\begin{array}{c}\text { Mengganti } \\
\text { komponen Exhaust } \\
\text { Valve yang rusak }\end{array}$ \\
\hline Injector & $500-1000$ jam & Pengujian tekanan \\
\hline
\end{tabular}

Sumber : Data Perawatan/Pemeriksaan Komponen di Kapal Westsea Gail 
Setiap perawatan melakukan suatu manajemen perawatan yang terdiri dari perencanaan (organizing), pelaporan (actualing), analisa (controlling), sehingga dalam menyusun suatu manajemen perawatan ini perlu mengerti tentang plan maintenance system, karena plan maintenance system ini adalah semua yang kita kerjakan harus dicatat atau ditulis sehingga sesuai dengan prosedur dalam plan maintenance system.Sistem perawatan mesin induk di atas kapal juga bisa menerapkan plan maintenance system, dimana tujuan dari sistem ini adalah untuk menyiapakan perangkat manajemen yang lebih baik dan meningkatkan keselamatan, baik awak kapal maupun peralatan.Sistem perawatan berencana modern terdiri banyaknya elemen seperti rencana kerja, control penyediaan, informasi dan instruksi.Pelaksanaan yang mudah adalah pertimbangan utama dari sistem ini, sehingga awak kapal secara cepat memiliki kepercayaan dari dalam menerapkan sistem ini.Seperti alat-alat yang ada di papan perawatan. Pengalaman menunjukkan bahwa untuk menunjukkan prosedur perawatan yang efisien adalah penting untuk memiliki pengaturan fleksibel, dengan memperhitungkan perubahan-perubahan kondisi dari komponen-komponen waktu seperti halnya pengaruh kondisi lingkungan terhadap umur operasionalnya

\section{SIMPULAN DAN SARAN}

A. Simpulan

1. Penanganan masalah akibat kerusakan pada exhaust valve mesin induk dapat dilakukan dengan :

a. Melakukan penggantian komponen-komponen katup buang (exhaust valve) yang sudah mengalami kerusakan., Exhaust Valve menurut jadwal pengecekannya dilakukan pada penggunaan 1500-2000 Jam kerja 
b. Melakukan pembersihan dari kerak-kerak pada setiap komponen katup.

c. Menyetel celah katup sesuai dengan instruksi manual book.

2. Melaksanakan perawatan exhaust valve pada mesin induk dilakukan dengan :

a. Melakukan perawatan pada exhaust valve secara teratur sesuai dengan jam kerja untuk menghindari kerusakan yang fatal.

b. Memberikan informasi yang berkesinambungan tentang perawatan, sehingga perwira yang baru naik kapal dapat mengetahui apa yang harus dikerjakan.

B. Saran

Mengingat pentingnya exhaust valve pada motor diesel maka harus diperhatikan :

1. Selalu memperhatikan pemakaian jam kerja (running hours) pada katup buang motor induk.

2. Harus memahami apa itu plan maintenance system dan harus dilaksanakan sesuai dengan jadwal.

3. Atasan dan bawahan harus dapat bekerja sama, koordinasi harus selalu berjalan dengan baik sehingga kalau ada masalah dapat segera diatasi. 


\section{DAFTAR PUSTAKA}

[1]. Firmarest, H. Pengoerasian Dan Perawatan Instalasi Mesin di

[2]. Kapal-Kapal Motor. Jakarta: PT. Asuka Bahari Nusantara, (2013)

[3]. Henry Sunaryo - Haryanto - Triyono, Perawatan dan Perbaikan Motor Diesel Penggerak Kapal.

[4]. Manulang, Plan Maintenance System, 1992.

[5]. NSOS, Manajemen Perbaikan dan Perawatan, Jakarta 1990.

[6]. Propessor Franz Feuleaux, Mesin, Pustaka Ilmia Laif 1875.

[7]. Sukur, M.Mar.E.. Perawatan Dan Perbaikan. Jakarta: Kementrian Perhubungan. (2014)

[8]. Van Maanen, Motor Diesel Kapal, Nautech Jilid II.

[9]. V.L. Maleev, M.E., DR. AM, Operasi dan Pemeliharaan Mesin Diesel,Erlangga Jakarta 1991.

[10]. Wiranto Arismunandar, Koichi Tsuda, Motor Diesel Putaran tinggi,PT. Pradnya Paramita Jakarta 2002. 